\title{
Erythropoietic protoporphyria without skin symptoms-you do not always see what they feel
}

\author{
Anne L. Y. Lecluse • Veronica C. M. Kuck-Koot • \\ Huib van Weelden • Vigfus Sigurdsson • \\ Ingrid M. Russel • Jorge Frank • \\ Suzanne G. M. A. Pasmans
}

Received: 21 February 2007 / Accepted: 18 June 2007 / Published online: 21 August 2007

(C) Springer-Verlag 2007

\begin{abstract}
Erythropoietic protoporphyria (EPP) is an inherited disorder of the porphyrin metabolism that often remains undiagnosed in children. We report on a 4-year-old girl who had been suffering for 1 year from recurrent painful crises affecting her hands, feet, and nose following sun exposure. Objective skin lesions were absent until the age of 6. Porphyrin analysis revealed elevated free erythrocyte protoporphyrin (FEP) levels confirming the diagnosis of EPP. This illustrates that skin lesions might be completely absent in children affected with EPP, a fact that has only been reported once previously. Because EPP can manifest with few and unspecific cutaneous symptoms or no skin lesions at all, like in this patient, the diagnosis of
\end{abstract}

A. L. Y. Lecluse • V. C. M. Kuck-Koot $(\bowtie) \cdot H$. van Weelden • V. Sigurdsson · S. G. M. A. Pasmans

Department of Dermatology and Allergology, Wilhelmina Children's Hospital, University Medical Centre, G02.124, P.O. Box 85500, 3508 GA Utrecht, The Netherlands

e-mail: v.c.m.kuck@umcutrecht.nl

\section{M. Russe}

Department of Pediatrics, Wilhelmina Children's Hospital, University Medical Centre, G02.124,

P.O. Box 85500,3508 GA Utrecht, The Netherlands

\section{J. Frank}

Department of Dermatology, University Hospital Maastricht, Maastricht, The Netherlands

J. Frank

Maastricht University Centre for Molecular Dermatology

(MUCMD), University Hospital Maastricht,

Maastricht, The Netherlands

J. Frank

Euregional Porphyria Centre Maastricht-Aachen (EPCMA), University Hospital Maastricht,

Maastricht, The Netherlands
EPP might be delayed or missed. EPP should be excluded in all photosensitive children, especially when discomfort is disproportionate to the extent of the cutaneous lesions. The clinic, pathophysiology, diagnosis, complications, and therapy of EPP are discussed.

Keywords Porphyrias - Erythropoietic protoporphyria . Ferrochelatase $\cdot$ Photosensitivity

$\begin{array}{ll}\text { Abbreviations } \\ \text { EPP } & \text { erythropoietic protoporphyria } \\ \text { FECH } & \text { ferrochelatase } \\ \text { ROS } & \text { reactive oxygen species } \\ \text { FEP } & \text { free erythrocyte protoporphyrin } \\ \text { UV } & \text { ultraviolet } \\ \text { UVB } & \text { ultraviolet-B } \\ \text { ALA } & \delta \text {-aminolevulinic acid }\end{array}$

\section{Introduction}

Erythropoietic protoporphyria (EPP) (OMIM 177000) results from a partial deficiency of ferrochelatase (FECH), the last enzyme in heme biosynthesis that is located in the mitochondrium [10, 13]. FECH catalyzes the insertion of iron into protoporphyrin IX to form heme (Fig. 1) [10]. Although overall EPP is a rare disease, it is the most common type of porphyria manifesting in childhood with an estimated prevalence of 1 in 130,000 [10,13,23].

The disease has no racial or sex predilection and no precipitating factors have been described to date $[10,20]$. The major clinical feature of EPP is cutaneous photosensitivity that usually commences early in infancy or childhood, affects the sun-exposed body sites, and worsens 
Fig. 1 In the mitochondrium, ferrochelatase catalyzes the formation of heme from protoporphyrin IX. $A L A: \delta$ aminolevulinic acid

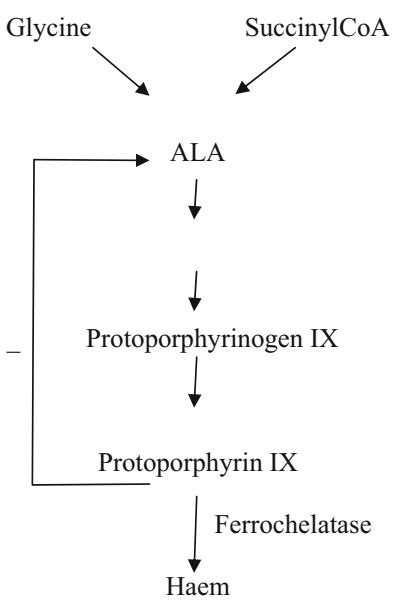

in spring and summer [10]. The symptoms include pain, burning, itching, erythema, and swelling, which can develop within minutes of sun exposure $[4,10,13,14]$. Petechiae, purpura, and vesicles may be seen, but are uncommon [4]. Typically, children experience relief when cooling the skin with cold water or wet towels [11]. Chronic UV (ultraviolet) exposure can lead to lichenification, postinflammatory hyperpigmentation, and scarring, particularly over the knuckles and on the nose [13, 23]. Of note, the cutaneous symptoms can be discrete and barely notable in early childhood despite significant subjective discomfort including burning and stinging sensations in the skin.

Here, we describe a girl with EPP with an unusual clinical course, demonstrating that parents and physicians cannot always recognize how much the patients suffer.

\section{Case report}

An otherwise healthy, 4-year-old Dutch Caucasian girl presented with a 1-year history of suddenly occurring severe itching and pain in the hands, feet, and nose after sunlight exposure. These sensations lasted up to 3 days, and she reported on three such incidents during the last 12 months. The symptoms developed either immediately or up to $8 \mathrm{~h}$ after UV exposure. Erythema or other skin manifestations were not seen. The condition worsened in the summer months and during vacations in sunny climates. Itching commenced immediately after sunlight exposure and reached a maximum at night. After a few hours, the itching changed into pain. Application of wet towels or cold baths led to partial relief, and the symptoms usually vanished spontaneously after a couple of cloudy days without intense UV exposure. Looking back, her parents also remembered that at the age of 1 year, during a summer vacation, she had suffered from an unexplained acute swelling of the hands and feet. At that time no specific diagnosis was made, besides the suspicion of an allergy. During that vacation at the sea side, the overall family life was disturbed because she was continuously agitated, cried a lot without an apparent reason, and did not sleep well.

Upon physical examination in our outpatient clinic at the age of 4 , she showed no skin symptoms except for few minimal excoriations on the dorsal aspects of the feet. The family history revealed eczema in the mother and atopy in the paternal grandmother, but was unremarkable regarding increased photosensitivity. Eventually, a pediatrician suggested the differential diagnoses polymorphic light eruption, warmth intolerance, or hypochondria, and the girl was treated unsuccessfully with antihistamines.

Due to continuation of her complaints, a pediatric dermatologist was consulted who suspected EPP despite the absence of cutaneous manifestations. Blood porphyrin analysis revealed elevated free erythrocyte protoporphyrin (FEP) levels of 9,821 $\mu \mathrm{g} / 1$ (normal 0-300 $\mu \mathrm{g} / \mathrm{l}$ ), confirming the diagnosis of EPP. Affirmative phototesting showed maximal cutaneous sensitivity at a wavelength of $400 \mathrm{~nm}$ (violet light). Full blood count and liver enzymes were normal.

Therapeutically, strict UV light avoidance, protective sunscreens, and annual follow-up visits were advised. Still, her photosensitivity did not improve, and mild hyperpigmentation and sores at her nose and upper lip as well as pronounced knuckles and progressive lichenification developed at the age of 6 . To date, she has not shown liver enzyme alterations.

\section{Discussion}

Here we present a girl with EPP who suffered from a significant decrease of quality of life due to severe itching and pain of the skin. Clinically, EPP is characterized by cutaneous photosensitivity manifesting early in life. Acute photosensitivity episodes include burning, stinging, and pruritus in sun-exposed skin, particularly on the nose, cheeks, and dorsal aspects of the hands, followed by erythema, edema, and wax-like scarring. Skin symptoms can occur within minutes of sun exposure, often starting early in spring time, continuing through the summer, and diminishing in fall and winter.

Interestingly though, our patient did not show any visible skin lesions until the age of 6 . Over the last 30 years there have been ten reports on children with EPP who developed mild to severe cutaneous photosensitivity and specific skin manifestations $[1,2,11,15,19-21,23,30$, 31]. With mild or absent visible skin symptoms, however, diagnosis may be delayed for several years or is not made at all because the discomfort experienced by the young patients is disproportionate to the objective cutaneous 
manifestations $[22,23]$. Thus, children with EPP are often labeled as hysterical, hypochondriac, or even malingering, a distressing situation for both the patients and their parents $[2,22]$. To the best of our knowledge the complete absence of visible skin lesions in early childhood EPP has only been described once to date [12].

The symptoms in EPP are associated with an overproduction and accumulation of lipophilic protoporphyrin as a result of FECH deficiency [28]. Excess deposition of protoporphyrin in the skin leads to cutaneous photosensitivity upon UV light exposure with maximum susceptibility at a wavelength around $400 \mathrm{~nm}$ (Soret band) [22]. Upon excitation, protoporphyrin exerts its phototoxic effects through the generation of reactive oxygen species (ROS). ROS can induce lipid peroxidation, oxidation of amino acids, and mediator release from mast cells, contributing to the acute photosensitivity, and protein cross-linking leading to cell membrane damage and cell death $[3,7,13,17,25]$.

The diagnosis of EPP is based on the clinical symptoms and verified by a significant increase of FEP (more than five times the normal level of 0 to $300 \mu \mathrm{g} / \mathrm{l}$ ) in peripheral erythrocytes $[15,18,28]$. Since protoporphyrin is a hydrophobic metabolite, it is not renally excreted. Hence, urinary porphyrin values are usually normal $[15,23]$. Another diagnostic modality includes fluorescence microscopy of erythrocytes [2, 17].

Histological changes are predominantly seen in the upper dermis and include deposition of amorphous material containing immunoglobulins, complement components, glycoproteins, acid glycosaminoglycans, and lipids around blood vessels [5, 21, 24, 26, 27, 29]. However, these alterations are not specific. Regardless of the aforementioned finding, we emphasize that it is unnecessary to take a skin biopsy if one of the cutaneous porphyrias is suspected because of two reasons. Firstly, simple non-invasive biochemical laboratory techniques can easily prove or exclude the presumptive diagnosis of porphyria. Secondly, any kind of external trauma, such as a biopsy or excision, inevitably constitutes an unnecessary risk for delayed or disturbed wound healing in porphyria patients.

The differential diagnoses of EPP include solar dermatitis, solar urticaria, polymorphous light eruption, lipoid proteinosis, hydroa vacciniforme, and lupus erythematosus $[2,22]$. Elevated FEP levels can also be found in lead poisoning, anemia, renal failure, cholestasis, and liver failure. However, these conditions are not associated with photosensitivity [13, 18, 23].

Beside the cutaneous manifestations, the most important concern in EPP patients is the development of cholestasis with rapid accumulation of protoporphyrin in hepatobiliary structures resulting in severe liver damage and hepatic failure. Although rarely occurring, progressive liver failure is a well-recognized complication in EPP, and about one third of EPP patients show biochemical liver abnormalities $[6,13]$. Therefore, liver function tests should be performed annually $[13,28]$. In our patient, no liver dysfunction has been detected so far.

Although in rare instances an autosomal recessive inheritance pattern has been described, EPP is a predominantly autosomal dominantly transmitted disorder with incomplete penetrance resulting from mutations in the FECH gene on chromosome 18q21.3 [31, 32]. To date, more than 65 different FECH mutations have been reported, reflecting the genetic heterogeneity encountered in EPP $[13,28]$. Recently, the genetic mechanisms underlying the cutaneous symptoms in EPP have been uncovered. It is clear now that only those individuals will develop skin symptoms who not only inherit a heterozygous $F E C H$ gene mutation on one parental allele, but also a specific intronic $F E C H$ polymorphism on the other parental allele [8]. Thus, clinically overt EPP results from a marked deficiency of FECH activity below a certain threshold due to co-inheritance of a specific FECH gene mutation with a low-penetrance IVS3-48C allele. Recent studies indicate that the frequency of the IVS3-48C allele shows a high degree of variability in different ethnic groups [9]. The identification of the molecular mechanisms underlying the manifestation of photosensitivity in EPP certainly has to be considered a milestone in porphyria research. Still, the development of protoporphyrin-induced hepatic disease and the molecular mechanisms governing the phenotype with severe liver injury are not well understood. It seems that other as yet unidentified factors may contribute to the pathogenesis of severe liver failure in EPP.

The current treatment modalities for EPP are limited and not effective in all patients [13]. In an ideal scenario, the harmful effects of exposure to visible light should be prevented. This can partially be achieved with sunscreens containing titanium oxide or zinc oxide. Common sunscreens, even those with high UV absorption capacity, do not block visible light and, thus, have no protective effect $[2,28]$.Consequent avoidance of UV light exposure and sun protection by protective clothing remains the most important measure in preventing acute photosensitivity and was also advised to our patient [13, 14, 18, 28]. The effectiveness of other modalities such as antioxidants (e.g., beta-carotene), cysteine, narrow-band UVB-phototherapy, and oral antihistamines remains doubtful and is certainly not of benefit in all patients. In the future, gene therapy approaches might play a role in the treatment of EPP because, e.g., normal ferrochelatase activity could be restored in vitro by transferring a wild-type copy of the FECH gene into cultured fibroblasts of EPP patients [16].

In conclusion, the diagnosis of EPP is often delayed or missed. Therefore, EPP should always be considered in photosensitive children, especially when the subjective 
discomfort is disproportionate to the extent of visible skin manifestations because we obviously do not always see what these patients feel. If cutaneous symptoms are completely absent, an accurate diagnosis is difficult and requires all diagnostic abilities of the attending physicians.

Acknowledgements JF is a board member of the European Porphyria Initiative (EPI) and was in part supported by grant no. A04155HS, GIS-Institut des Maladies rares: Network on rare diseases to the European Porphyria Initiative (EPI), and a grant from the European Union to the European Porphyria Network (EPNET).

\section{References}

1. Alemzadeh R, Feehan T (2004) Variable effects of beta-carotene therapy in a child with erytropoietic protoporphyria. Eur J Pediatr 163:547-549

2. Burr RD, Tyler WB, Miller OF (1993) Burning discomfort and swelling of the hands and face of a young child-erythropoietic protoporphyria (EPP). Arch Dermatol 29(5):635-638

3. De Goeij AF, van Steveninck J (1976) Photodynamic effects of protoporphyrin on cholesterol and unsaturated fatty acids in erythrocyte membranes in protoporphyria and in normal red blood cells. Clin Chim Acta 68:115-122

4. DeLeo VA, Poh-Fitzpatrick M, Mathews-Roth M, Harber LC (1976) Erythropoietic protoporphyria-10 years experience. Am J Med 60:8-22

5. Epstein JH, Tuffanelli DL, Epstein WL (1973) Cutaneous changes in the porphyrias-a microscopic study. Arch Dermatol 107:689-698

6. Frank M, Doss MO (1991) Severe liver disease in protoporphyria. In: Vermeer BJ, Wuepper KD, van Vloten WA, Baart de la Faille $\mathrm{H}$, van der Schoroeff JG (eds) Current problems in dermatology. Basel, Karger-Verlag, pp 160-167

7. Goldstein BD, Harber LC (1972) Erythropoietic protoporphyrialipid peroxidation and red cell membrane damage associated with photohemolysis. J Clin Invest 51:892-902

8. Gouya L, Puy H, Robreau AM, Bourgeois M, Lamoril J, Da Silva V, Grandchamp B, Deybach JC (2002) The penetrance of dominant erythropoietic protoporphyria is modulated by expression of wildtype FECH. Nat Med 30:27-28

9. Gouya L, Martin-Schmitt C, Robreau AM, Austerlitz F, Da Silva V, Brun P, Simonin S, Lyoumi S, Grandchamp B, Beaumont C, Puy H, Deybach JC (2006) Contribution of a common singlenucleotide polymorphism to the genetic predisposition for erythropoietic protoporphyria. Am J Hum Genet 78(1):2-14

10. Gross U, Hoffmann GF, Doss MO (2000) Erythropoietic and hepatic porphyrias. J Inherit Metab Dis 23(7):641-661

11. Krekels GA, Neumann HA (2000) Diagnostic image-erythropoietic protoporphyria. Ned Tijdschr Geneeskd 144(48):2303

12. Labrousse AL, Salmon-Her V, Eschard C, Kalis B, Leonard F, Bernard P (1998) Recurrent painful hand crisis in a 4-year-old girl, revealing an erythropoietic protoporphyria. Eur J Dermatol 8 (7):515-516
13. Lim HW, Murphy GM (1996) The porphyrias. Clin Dermatol 14 (4):375-387

14. Mascaro JM (1992) Porphyrias in children. Pediatr Dermatol 9 (4):371-372

15. Mather MK, Sau P (1998) Pathological case of the monthErythropoietic protoporphyria. Arch Pediatr Adolesc Med 152 (6):603-604

16. Mathews-Roth MM, Michel JL, Wise RJ (1995) Amelioration of the metabolic defect in erythropoietic protoporphyria by expression of human ferrochelatase in cultured cells. J Invest Dermatol 104(4):497-499

17. Murphey GM (1999) The cutaneous porphyrias: a review. Br J Dermat 140:573-581

18. Murphey GM (2003) Diagnosis and management of the erythropoietic porphyrias. Dermatol Ther 16:57-64

19. Ozasa S, Yamamoto S, Maeda M, Inada S, Yanai S, Takagaki K (1977) Erythropoietic protoporphyria-report of a family and clinical review. J Dermatol 4(3):85-89

20. Patel GK, Weston J, Derrick EK, Hawk JLM (2000) An unusual case of erythropoietic protoporphyria. Clin Exp Dermatol 25 (5):406-408

21. Peterka ES, Fusaro RM, Goltz RW (1965) Erythropoietic protoporphyria. II- histological and histochemical studies of cutaneous lesions. Arch Dermatol 92:357-361

22. Piotte M, Hassoun A, Bourlond A, Cornu G (1989) Erythropoietic protoporphyria in a child. Eur J Pediatr 148(6):507-509

23. Rector JT, DeLoach-Banta LJ, Barrett TL, Tunnessen WW (1993) Picture of the month. Erythropoietic protoporphyria. Am J Dis Child 147(1):73-74

24. Ryan EA, Madill GT (1968) Electron microscopy of the skin in erythropoietic protoporphyria. Br J Dermatol 80:561-570

25. Sandberg S, Romslo I (1981) Porphyrin-induced photodamage at the cellular and the subcellular level as related to the solubility of the porphyrin. Clin Chim Acta 109:193-201

26. Sasai Y (1973) Erythropoietic protoporphyria. Histochemical study of hyaline material. Acta Derm Venereol 53:179-184

27. Schnait FG, Wolff K, Konrad K (1975) Erythropoietic protoprophyria-submicroscopic events during the acute photosensitivity flare. Br J Dermatol 92:545-557

28. Schneider-Yin X, Gouya L, Meier-Weinand A, Deybach JC, Minder EI (2000) New insights into the pathogenesis of erythropoietic protoporphyria and their impact on patient care. Eur J Pediatr 159(10):719-725

29. Timonen K, Kariniemi AL, Niemi KM, Teppo AM, Tenhunen R, Kauppinen R (2000) Vascular changes in erythropoietic protoporphyria: histopathologic and immunohistochemical study. J Am Acad Dermatol 43(3):489-497

30. Torinuku W, Miura T (1983) Erythropoietic protoporphyria showing solar purpura. Dermatologica 167:220-222

31. Varma SA, Haworth A, Keefe M, Anstey AV (2000) Delayed onset of cutaneous symptoms in erythropoietic protoporphyria. $\mathrm{Br}$ J Dermatol 143:221-223

32. Whatley SD, Mason NG, Khan M, Zamiri M, Badminton MN, Missaoui WN, Dailey TA, Dailey HA, Douglas WS, Wainwright NJ, Elder GH (2004) Autosomal recessive erythropoietic protoporphyria in the United Kingdom: prevalence and relationship to liver disease. J Med Genet 41(8):e105 